\title{
Production of (Mn,Fe)-Carbide Containing Low Phosphorus by Carbothermic Reduction of Mn Oxide and Fe Oxide
}

\author{
Dong-Yuk KIM, ${ }^{1)}$ Hyun-Soo $\mathrm{KIM}^{21}$ and Sung-Mo JUNG ${ }^{3 / *}$ \\ 1) Graduate Institute of Ferrous Technology (GIFT), POSTECH, Cheongam-ro 77, Pohang, 790-784 Korea. \\ 2) Ironmaking Research Group, POSLAB, POSCO, Donghaean-ro 6261, Pohang, 790-783 Korea. \\ 3) Graduate Institute of Ferrous Technology (GIFT), POSTECH, Pohang, 790-784 Korea.
}

(Received on July 30, 2014; accepted on December 3, 2014)

\begin{abstract}
The dephosphorization process for high phosphorus iron ores have recently been studied employing several methods. However, few researches of phosphorus removal from high phosphorus manganese ores have been carried out compared with those about the high phosphorus iron ores. As a potential approach for the removal of phosphorus contained in the composite, the formation of ( $\mathrm{Mn}$, Fe)-carbide by the carbothermic reduction of the oxides of manganese and iron was investigated at $1200^{\circ} \mathrm{C}$ in $\mathrm{H}_{2}$ atmosphere employing thermogravimetric analysis (TGA). It was confirmed that the phosphorus did not dissolve into the manganese iron carbide, $(\mathrm{Mn}, \mathrm{Fe})_{7} \mathrm{C}_{3}$ even though it has the high reactivity with $\mathrm{Fe}$ and $\mathrm{Mn}$. Instead, the phosphorus generated by the decomposition of $\mathrm{Ca}_{3}\left(\mathrm{PO}_{4}\right)_{2}$ reacted with $\mathrm{Fe}$ and $\mathrm{Mn}$ to form $(\mathrm{Fe}, \mathrm{Mn})_{3} \mathrm{P}$. According to EPMA line mapping, (Mn,Fe)-carbide and (Fe,Mn)-phosphide coexist in the reduced particle. The current results could be applied for a promising treatment of dephosphorization of high phosphorous ores due to the low solubility of phosphorus in carbide.
\end{abstract}

KEY WORDS: dephosphorization; carbothermic reduction; carburization; manganese iron carbide; metallic phosphide; solubility; distribution.

\section{Introduction}

TWIP (Twinning-Induced Plasticity) steel containing high manganese has been developed as a new-generation steel to meet the requirements for the advanced high strength steel (AHSS). TWIP steel has both high strength and elongation, whose utility and application are expected to continuously increase in future. Due to the increased consumption of manganese in steel industry, high grade manganese ores have gradually depleted with the great increase of its price. Thus, manufacturers of manganese-based alloys will have no choice but to use the low grade ores with impurities. One of the principal impurities in manganese ores is phosphorus which is difficult to be removed in smelting reduction process. ${ }^{1)}$ Most of the phosphorus is removed in oxidizing conditions by the conventional method such as BOF (Basic Oxygen Furnace), however, whose process can bring out a significant loss of manganese because of the preferential oxidation of manganese. ${ }^{2)}$

There have been several researches about carbothermic solid state reduction of manganese ores to improve the process efficiency in the extraction of $\mathrm{Mn}^{3}{ }^{3)}$ In the process, the manganese iron carbide, $(\mathrm{Mn}, \mathrm{Fe})_{\mathrm{x}} \mathrm{C}_{\mathrm{y}}$, can be formed, which might be the one of the various dephosphorization methods because the solubility of phosphorus in carbide might be expected to be low. The presence of carbon can enhance the dephosphorization of ferromanganese due to the increase in the activity coefficient of phosphorus with increasing carbon content. Although the effect of carbon on the dephosphorization of ferromanganese in liquid state is more significant, its extent would have the similar tendency in the manganese iron carbide in the solid state. ${ }^{4)}$ In addition, the carbon activity can be increased by phosphorus due to the repulsive force exerted between them (interaction parameter in iron alloys, $e_{P}^{C}=0.126$ ), which results in the low solubility of phosphorus in carbide with high content of carbon. ${ }^{5)}$ Above all, it is not possible to carburize phosphorus because it requires huge amount of energy for the formation of phosphorus carbide. That is, in contrast with the computational prediction ${ }^{6}$ estimating the possible crystal structure of phosphorus carbide, in practice, it is extremely difficult to synthesize phosphorus carbide in general experimental conditions of reduction system.

Based on the above evidence, the removal of phosphorus could be carried out through the carbide formation from high phosphorus manganese ores. However, the hypothesis should need precise experimental proofs for the commercialization of dephosphorization process. Therefore, the current research aims to investigate the behavior of phosphorus during the formation of $(\mathrm{Mn}, \mathrm{Fe})$-carbide with the intention of the basis applying it as dephosphorization treatment.

* Corresponding author: E-mail: smjung@postech.ac.kr

DOI: http://dx.doi.org/10.2355/isijinternational.55.504 


\section{Experimental}

\subsection{Materials Preparation}

To confirm the low solubility of phosphorus in carbide, the reagent-grade chemicals of $\mathrm{MnO}$ (Aldrich chemistry, 99\% purity, particle size: less than $250 \mu \mathrm{m}$ ) and $\mathrm{Fe}_{3} \mathrm{P}$ (Alfa Aesar, $99.5 \%$ purity) were uniformly mixed with synthetic graphite $(99.7 \%$ purity, mean particle size: $5 \mu \mathrm{m})$ as carbothermic reducing agent for 30 min employing the mixing apparatus (SPEX SamplePrep). The mass ratio of $\mathrm{MnO}$, $\mathrm{Fe}_{3} \mathrm{P}$ and graphite in the mixture is $6: 1: 2$. Then cylindrical tablets of $10 \mathrm{~mm}$ diameter were produced by pressing $0.5 \mathrm{~g}$ of the mixture at $40 \mathrm{MPa}$ into a cylindrical mold. The use of $\mathrm{Fe}_{3} \mathrm{P}$ is not only for phosphorus-containing compound but also for the confirmation of the phosphorus diffusion in the course of carburization of $\mathrm{Fe}$ in $\mathrm{Fe}_{3} \mathrm{P}$ with graphite.

In addition, the reagent-grade chemicals of $\mathrm{MnO}_{2}, \mathrm{Fe}_{2} \mathrm{O}_{3}$ and $\beta-\mathrm{Ca}_{3}\left(\mathrm{PO}_{4}\right)_{2}$ were prepared to represent the high phosphorus manganese ores. $\mathrm{MnO}_{2}$ (Aldrich chemistry, $>99 \%$ purity) was in size of greater than $63 \mu \mathrm{m}$ and less than $250 \mu \mathrm{m}, \mathrm{Fe}_{2} \mathrm{O}_{3}$ was in size of $1 \mu \mathrm{m}$ with $99.9 \%$ purity. Because phosphorus exists mainly as apatite in manganese ores, $\beta-\mathrm{Ca}_{3}\left(\mathrm{PO}_{4}\right)_{2}$ of $10 \mu \mathrm{m}$ diameter was used as phosphorus-containing compound in the current experiment. The mixture of oxides and graphite was pelletized in the same order as above. The mass ratio of $\mathrm{MnO}_{2}, \mathrm{Fe}_{2} \mathrm{O}_{3}, \mathrm{Ca}_{3}\left(\mathrm{PO}_{4}\right)_{2}$ and graphite in the mixture is $6: 1: 0.5: 2$, which was normalized from the composition of high phosphorus manganese ore.

The slightly higher amount of graphite required for the carburization of reduced Mn was added to the samples with reference to the stoichiometric amount of carbon for the formation of $(\mathrm{Mn}, \mathrm{Fe})_{7} \mathrm{C}_{3}$ according to the following reaction:

$$
x \mathrm{MnO}+y \mathrm{Fe}+\left\{\frac{3(x+y)}{7}+x\right\} \mathrm{C}=\frac{(x+y)}{7}(\mathrm{Mn}, \mathrm{Fe})_{7} \mathrm{C}_{3}+x \mathrm{CO}
$$

The type of $(\mathrm{Mn}, \mathrm{Fe})$-carbide can be changed according to the different ratio of $\mathrm{Mn} / \mathrm{Fe}$ in carbide. The added amount of graphite was adjusted in such a way that $(\mathrm{Mn}, \mathrm{Fe})$-carbide containing highest carbon content should be $(\mathrm{Mn}, \mathrm{Fe})_{7} \mathrm{C}_{3}$ with reference to the manganese ores with higher ratio of $\mathrm{Mn}$ to $\mathrm{Fe}$.

\subsection{Experimental Procedure}

High temperature thermogravimetric analysis (TGA) (RUBOTHERM, Germany) was employed to form carbide by measuring the weight change with an accuracy of $0.01 \mathrm{mg}$. An alumina crucible $(12.5 \mathrm{~mm}$ ID and $10 \mathrm{~mm}$ Height) containing about $0.5 \mathrm{~g}$ of pellet was suspended by $\mathrm{Pt}$ wire and was then placed into the isothermal zone of the furnace. The furnace temperature was controlled by a thermocouple located close to the wall of the alumina working tube fitted in the furnace. Sample temperature was monitored by another thermocouple placed just below the bottom of the crucible. The weight change of the sample due to reduction and carburization was recorded on line with a computer. After the reaction chamber was purged with $\mathrm{Ar}$ gas of high purity during $30 \mathrm{~min}$, and then $1000 \mathrm{~mL} / \mathrm{min}$ of high purity $\mathrm{H}_{2}$ gas replaced Ar gas using a mass flow controller. The carbothermic reduction of $\mathrm{MnO}$ was the fastest in $\mathrm{H}_{2}$ gas due to the increased diffusivity of $\mathrm{CO}$ in atmosphere gas. ${ }^{7)}$ Accordingly, all of the experiments were carried out in $\mathrm{H}_{2}$ atmosphere to instantaneously form the manganese iron carbide. The isothermal reduction experiments were performed rapidly by heating up the TGA furnace at $100^{\circ} \mathrm{C} /$ min to $1200^{\circ} \mathrm{C}$. After completing the reaction, the sample was purged with Ar gas for rapid cooling.

\subsection{Analysis Methods}

The reduced sample was analyzed by X-ray diffraction (XRD), scanning electron microscope (SEM) with EDS and EPMA for the identification of phases and morphology observation. X-ray diffraction (D8 Advance, Bruker-AXS $\mathrm{GmbH}$ ) using a $\mathrm{Cu}-\mathrm{K} \alpha \mathrm{X}$-ray source was done by scanning from 20 to 80 degree at $2 \mathrm{~s} / \mathrm{step}$ with a step size of 0.02 degree. The voltage was $40 \mathrm{kV}$ with a current of $40 \mathrm{~mA}$.

The cross-section of the sample was mirror-polished with a $1 \mu \mathrm{m}$ diamond suspension before each point in the samples was analyzed by employing FE-EPMA (JEOL JXA-8530F) operated at $15 \mathrm{kV}$ and a $50 \mathrm{nA}$ beam current. The EDS (energy dispersive spectroscopy) in conjunction with FE-SEM operating at $15 \mathrm{kV}$ was used to perform semi-quantitative chemical analysis at different points within the samples with time.

\section{Results and Discussion}

\subsection{Carbothermic Reduction of $\mathrm{MnO}$ and $\mathrm{Fe}_{3} \mathrm{P}$}

Based on the theoretical consideration about the effect of carbon on dephosphorization as mentioned previously, the solubility of phosphorus in carbide would be measured by the carburization of manganese oxide with phosphoruscontaining compound. Accordingly, the preliminary experiments were performed to confirm the low solubility of phosphorus in carbide. That is, the carbothermic reduction of pure $\mathrm{MnO}$ and $\mathrm{Fe}_{3} \mathrm{P}$ with graphite was carried out at $1200^{\circ} \mathrm{C}$ in $\mathrm{H}_{2}$ atmosphere and the fractional reduction of the sample in the progress of reduction and carburization reaction was evaluated with time as shown in Fig. 1. The fractional reduction was calculated with the weight change of the pellets according to Eq. (2) under the assumption that the reduction of manganese oxide by $\mathrm{CO}$ is equal to the carbon

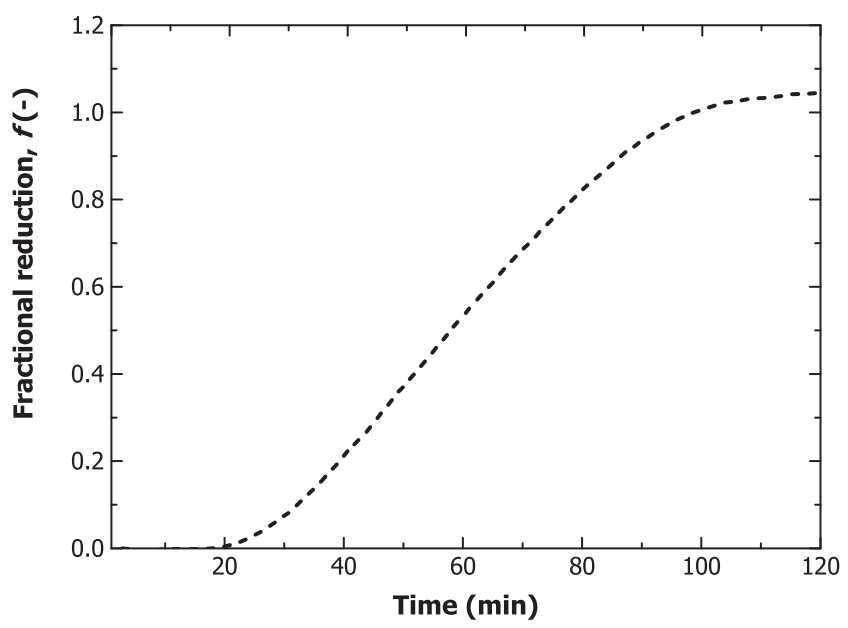

Fig. 1. Carbothermic reduction of $\mathrm{MnO}$ and $\mathrm{Fe}_{3} \mathrm{P}$ with graphite at $1200^{\circ} \mathrm{C}$ in $\mathrm{H}_{2}$ atmosphere. 
amount for the gasification reaction:

$$
f=\frac{\text { oxygen removed }}{\text { total removable oxygen }}=\frac{\Delta W_{t}}{W_{i} \times M}
$$

where $W_{i}$ is the initial pellet weight before reduction $(\mathrm{g})$, $\Delta W_{t}$ is the pellet weight decrease (g) during time, $t$. In Eq. (2), $M$ represents the fraction of weight loss corresponding to complete reduction of manganese oxide. The fractional reduction value higher than unity might be ascribed to the additional weight loss resulted from the vaporization of phosphorus and manganese.

According to XRD analysis shown in Fig. 2, a new phase was identified to be $(\mathrm{Mn}, \mathrm{Fe})_{7} \mathrm{C}_{3}$ even if the corresponding peaks actually represent the $\mathrm{Mn}_{7} \mathrm{C}_{3}$ phase in the XRD database. It is the stable carbide structure from the carburization of $\mathrm{MnO}$ by intermediate $\mathrm{CO}-\mathrm{CO}_{2}$ gas at $1200^{\circ} \mathrm{C}$ as shown in Fig. 3. In Fig. 3, the carbon activity $\left(a_{\mathrm{c}}\right)$ and oxygen potential $\left(p_{\mathrm{O}_{2}}\right)$ can be changed dependently along the line for the different ratio of $\mathrm{CO}$ to $\mathrm{CO}_{2}$ at the fixed temperature.

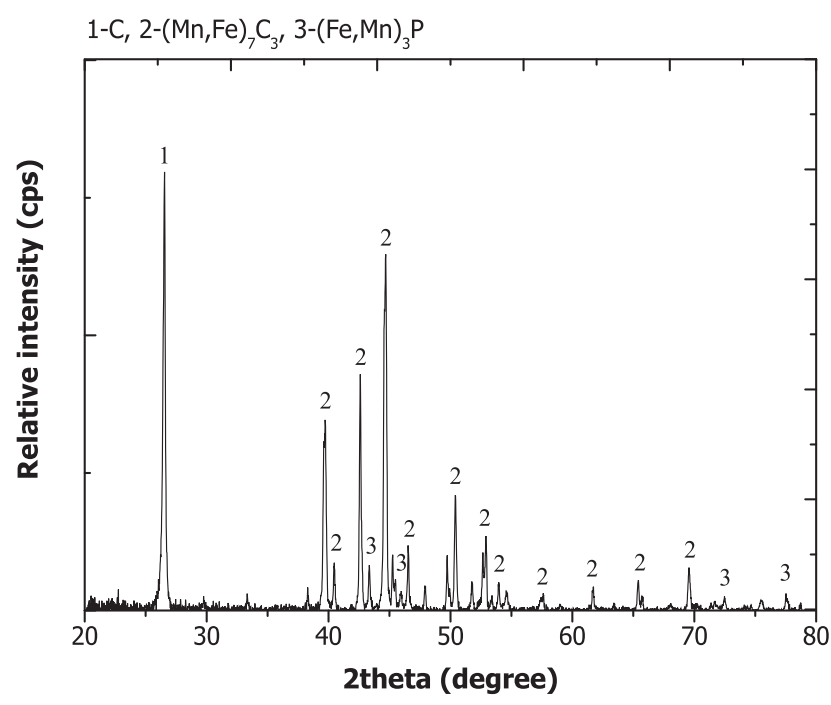

Fig. 2. XRD patterns of the carbothermically reduced sample comprising $\mathrm{MnO}$ and $\mathrm{Fe}_{3} \mathrm{P}$ at $1200^{\circ} \mathrm{C}$ in $\mathrm{H}_{2}$ atmosphere.

Mn-O-C, $1^{\circ 00} \mathrm{C}$

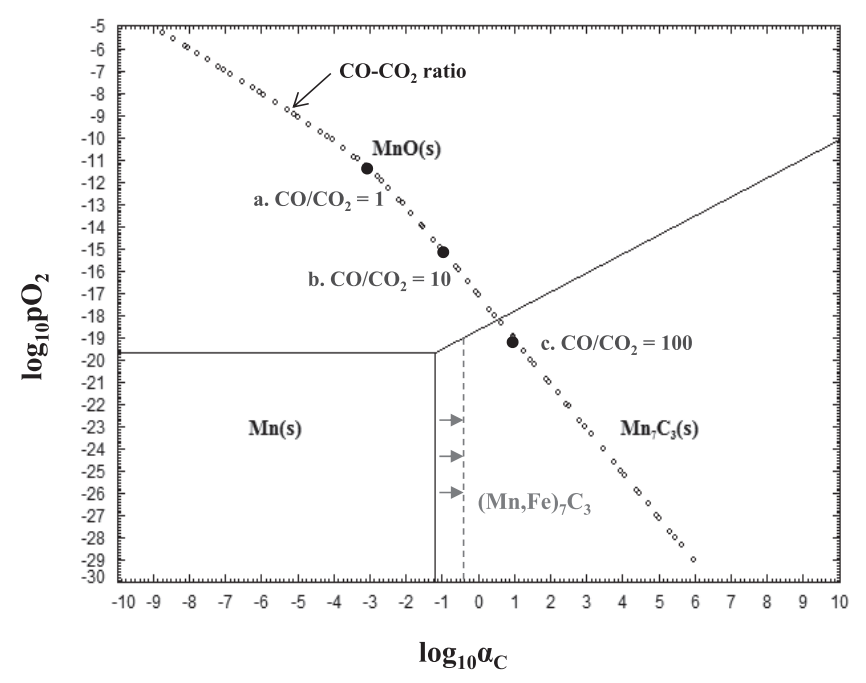

Fig. 3. Mn-O-C phase stability diagram at $1200^{\circ} \mathrm{C}$ as a function of oxygen partial pressure and the activity of carbon.
For example, the points $\mathrm{a}, \mathrm{b}$ and $\mathrm{c}$ were selected for some typical values of $\mathrm{CO} / \mathrm{CO}_{2}$ ratio. From the line of $\mathrm{CO} / \mathrm{CO}_{2}$ ratio in Fig. 3, $\mathrm{Mn}_{7} \mathrm{C}_{3}$ could be formed more easily in the condition of high $\mathrm{CO} / \mathrm{CO}_{2}$ ratio from the thermodynamic viewpoint.

Manganese and iron are very similar elements from viewpoints of physical characteristics such as the atomic radius and density, and they easily substitute each other in the progress of carbide formation. ${ }^{8)}$ In other words, iron can be substituted for manganese in manganese carbide to transform into the manganese iron carbide and manganese is also substituted for iron in $\mathrm{Fe}_{3} \mathrm{P}$. ${ }^{9)}$ The graphite in the sample remained after complete formation of carbide in XRD analysis. The carbon activity for the formation of manganese iron carbide, $(\mathrm{Mn}, \mathrm{Fe})_{7} \mathrm{C}_{3}$, can be increased depending on the amount of replaced iron as shown in Fig. 3. Since the bonding of substituted $\mathrm{Fe}$ and $\mathrm{C}$ is weaker than $\mathrm{Mn}-\mathrm{C}$ bonding in the carbide lattice, ${ }^{5)}$ the formed $(\mathrm{Mn}, \mathrm{Fe})_{7} \mathrm{C}_{3}$ is less stable than $\mathrm{Mn}_{7} \mathrm{C}_{3}$ with the higher activity of carbon. It can also cause the activity of $\mathrm{Mn}$ to relatively increase.

The behavior of phosphorus could simultaneously be predicted in relation to the carburization of $\mathrm{Mn}$ and $\mathrm{Fe}$ employing EPMA area mapping results shown in Fig. 4. The location of $(\mathrm{Mn}, \mathrm{Fe})_{7} \mathrm{C}_{3}$ was apparently identified by the overlapped areas of $\mathrm{Mn}, \mathrm{Fe}$ and $\mathrm{C}$ while the areas overlapped by $\mathrm{Mn}, \mathrm{Fe}$ and $\mathrm{P}$ were believed to represent $(\mathrm{Mn}, \mathrm{Fe})_{3} \mathrm{P}$. For more accurate identification of each element, the EPMA line mapping was carried out focusing on a particle containing $(\mathrm{Mn}, \mathrm{Fe})_{7} \mathrm{C}_{3}$ and $(\mathrm{Fe}, \mathrm{Mn})_{3} \mathrm{P}$ as shown in Fig. 5. The most impressive thing is that the distribution of phosphorus is opposite to that of carbon over the line profile. In addition, the phosphorus concentration in the regions of high carbon concentration was measured to be almost 0 mass $\%$. This indicates that phosphorus was not dissolved in manganese iron carbide, $(\mathrm{Mn}, \mathrm{Fe})_{7} \mathrm{C}_{3}$, even though it could react with $\mathrm{Fe}$ and $\mathrm{Mn}$. As previously explained, phosphorus did not participate in the formation of carbide with $\mathrm{Mn}$ and $\mathrm{Fe}$ due to the repulsive force with carbon.

\subsection{Carbothermic Reduction of $\mathrm{MnO}_{2}, \mathrm{Fe}_{2} \mathrm{O}_{3}$ and $\mathrm{Ca}_{3}\left(\mathrm{PO}_{4}\right)_{2}$}

3.2.1. Effect of Phosphorus on the Formation Mechanism of Carbide

High $\mathrm{P}$ manganese ore has complex composition containing several gangue compounds such as $\mathrm{SiO}_{2}, \mathrm{Al}_{2} \mathrm{O}_{3}, \mathrm{MgO}$, $\mathrm{Na}_{2} \mathrm{O}$, etc. ${ }^{10)}$ Because the gangue components of relatively small amount might interact with phosphorus in ores during the formation of manganese iron carbide, the reactions among the major compounds should be studied prior to that of high P manganese ore. Based on the experimental results using the reagent-grade chemicals, the interaction between manganese iron carbide and phosphorus in high $\mathrm{P}$ manganese ore was investigated. That is, the carbothermic reduction of $\mathrm{MnO}_{2}, \mathrm{Fe}_{2} \mathrm{O}_{3}$ and $\mathrm{Ca}_{3}\left(\mathrm{PO}_{4}\right)_{2}$ was carried out at several temperatures in $\mathrm{H}_{2}$ atmosphere. Figure 6 shows the change in the fractional reduction of the sample with time, which was divided into two stages across the fractional reduction of 0.55 . The critical fractional reduction was calculated for the reduction stage where the oxygen contained in both $\mathrm{MnO}_{2}$ and $\mathrm{Fe}_{2} \mathrm{O}_{3}$ was only removed by $\mathrm{H}_{2}$. That is, the first stage represents the reduction of $\mathrm{MnO}_{2}$ to $\mathrm{MnO}$ with that of 


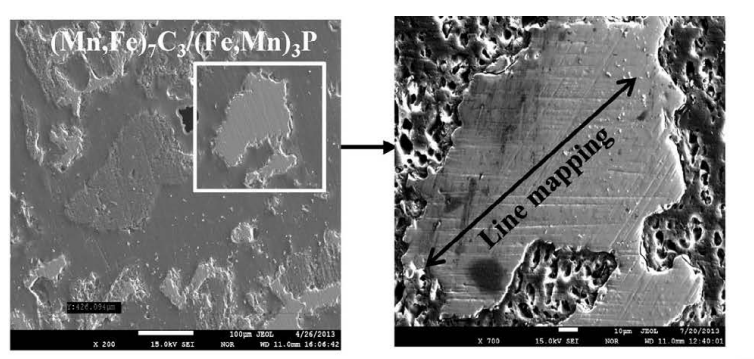

$<$ Mass \% >

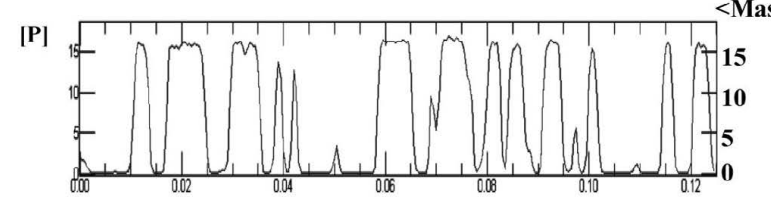

$[\mathrm{C}]$

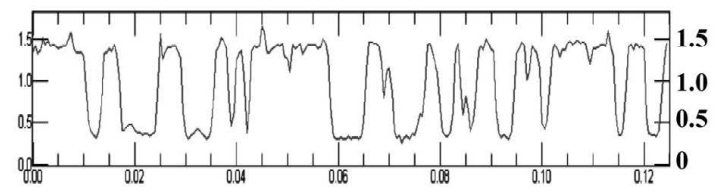

$[\mathrm{Fe}]$

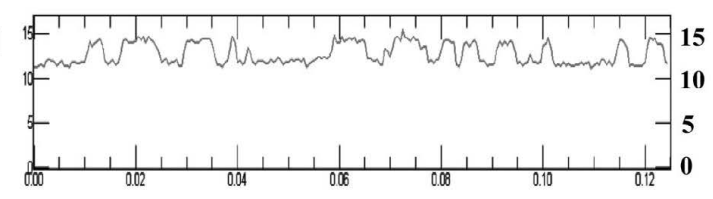

[Mn]

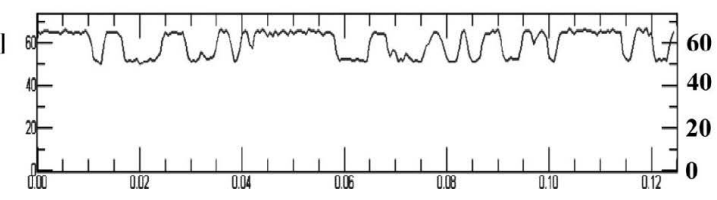

Fig. 5. EPMA line mapping (mass\%) of the carbothermically reduced sample comprising $\mathrm{MnO}$ and $\mathrm{Fe}_{3} \mathrm{P}$ at $1200^{\circ} \mathrm{C}$ in $\mathrm{H}_{2}$ atmosphere.

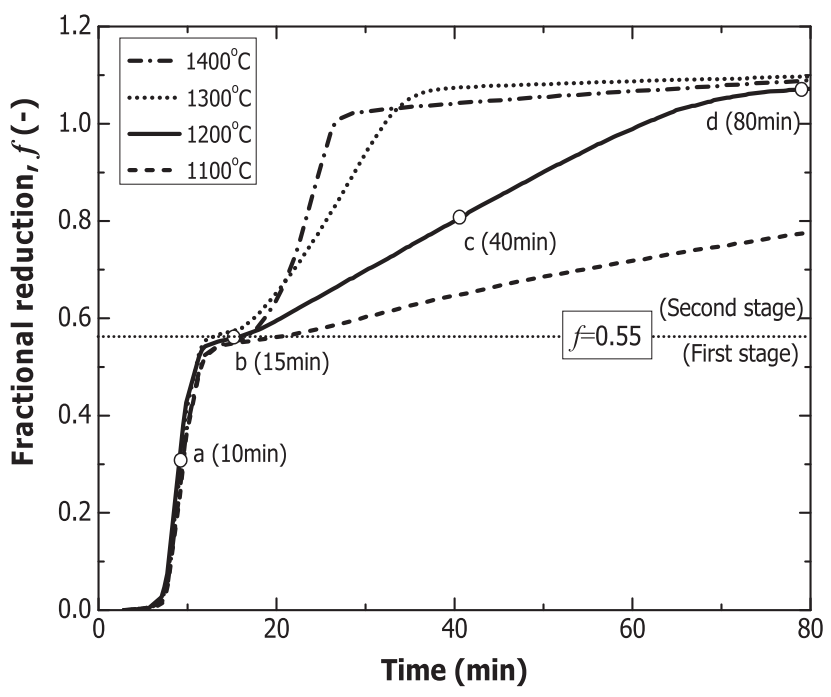

Fig. 6. Carbothermic reduction of $\mathrm{MnO}_{2}, \mathrm{Fe}_{2} \mathrm{O}_{3}$ and $\mathrm{Ca}_{3}\left(\mathrm{PO}_{4}\right)_{2}$ in $\mathrm{H}_{2}$ atmosphere in the temperature range of 1100 to $1400^{\circ} \mathrm{C}$.

$\mathrm{Fe}_{2} \mathrm{O}_{3}$ to metallic $\mathrm{Fe}$ by $\mathrm{H}_{2}$ according to the following reactions:

$$
\begin{aligned}
& \mathrm{MnO}_{2}+\mathrm{H}_{2} \rightarrow \mathrm{MnO}+\mathrm{H}_{2} \mathrm{O} \\
& \mathrm{Fe}_{2} \mathrm{O}_{3}+3 \mathrm{H}_{2} \rightarrow 2 \mathrm{Fe}+3 \mathrm{H}_{2} \mathrm{O}
\end{aligned}
$$

As shown in Fig. 6, these reactions started while raising temperatures and were completed as soon as reaching the target temperatures, and the reduction rates in the first stage were almost similar in the temperature range investigated. On the other hand, the second stage corresponds to the carburization of $\mathrm{MnO}$ and $\mathrm{Fe}$ by carbon, resulting in the formation of manganese iron carbide by Reaction (5):

$$
\mathrm{MnO}+\mathrm{Fe}+\mathrm{C} \rightarrow(\mathrm{Mn}, \mathrm{Fe}) \text { carbide }+\mathrm{CO}
$$

The rate of carburization increased with increasing temperature, which is believed to be limited by the interfacial Boudouard reaction. The carburization of $\mathrm{MnO}$ by $\mathrm{CO}$ was improved with increasing temperature by means of the faster transport of $\mathrm{CO}_{2}$ within the reactant mixture to the carbon particles. ${ }^{11)}$ Therefore, the formation of carbide was completed in the temperatures above $1100^{\circ} \mathrm{C}$ where $\mathrm{CO}_{2}$ becomes significantly unstable in the presence of carbon, resulting in the regeneration of $\mathrm{CO} .^{7,12)}$

The rate of carburization can be utilized to figure out how the phosphorus affects the formation of manganese iron carbide by comparing the current result with those reported by the previous researches. The rate-controlling step in the second stage could be estimated by calculating the apparent activation energy value by Eq. (6). That is, the apparent activation energy $\left(E_{\mathrm{A}}\right)$ of carburization can be calculated by plotting the temperature dependence of the apparent rate constant:

$$
k=k_{0} \exp \left(-E_{\mathrm{A}} / R T\right)
$$

where $E_{\mathrm{A}}$ is the activation energy and $k$ is a rate constant which can be derived from a rate equation of the form:

$$
\frac{\mathrm{dr}}{\mathrm{dt}}=k \cdot p^{n}
$$

where $\mathrm{dr} / \mathrm{dt}$ represent the reaction rate (fractional reduction/ time), $p$ is the pressure of the reducing gas and $\mathrm{n}$ is the order of reaction. The Arrhenius plot between the rate constant and the reciprocal of temperature in the second stage around the fractional reduction of 0.75 was presented in Fig. 7. The activation energy was calculated to be $207.4 \mathrm{~kJ} / \mathrm{mol}$, which might indicate that the carburization process is limited by the gasification of graphite according to the previous data reported by Kor and Rankin. ${ }^{13,14)}$

Since the reaction mechanism determined by the calculation of apparent activation energy is not decisive but quite indicative, the rate-controlling step attempted to be confirmed by the solid state reaction model previously derived. Direct solid-solid reactions are very slow and most of the solid state reactions occur via gaseous intermediate. Therefore, the kinetic model for the manganese iron carbide formed by intermediate $\mathrm{CO}-\mathrm{CO}_{2}$ gases in solid state can be considered by applying the intrinsic transport model developed by Wynnyckyj and Rsukin ${ }^{15)}$ which is for solid state reactions between powders in pellets or beds of reacting mixtures where the rate-limiting step is diffusion of a gaseous intermediate through the pore space.

By applying the intrinsic transport model ${ }^{16)}$ only according to Eq. (8), in this model, the fractional conversion is expressed in terms of the component on the surface of which the gaseous intermediate, $\mathrm{CO}_{2}$ is consumed, that is the graphite surface: 


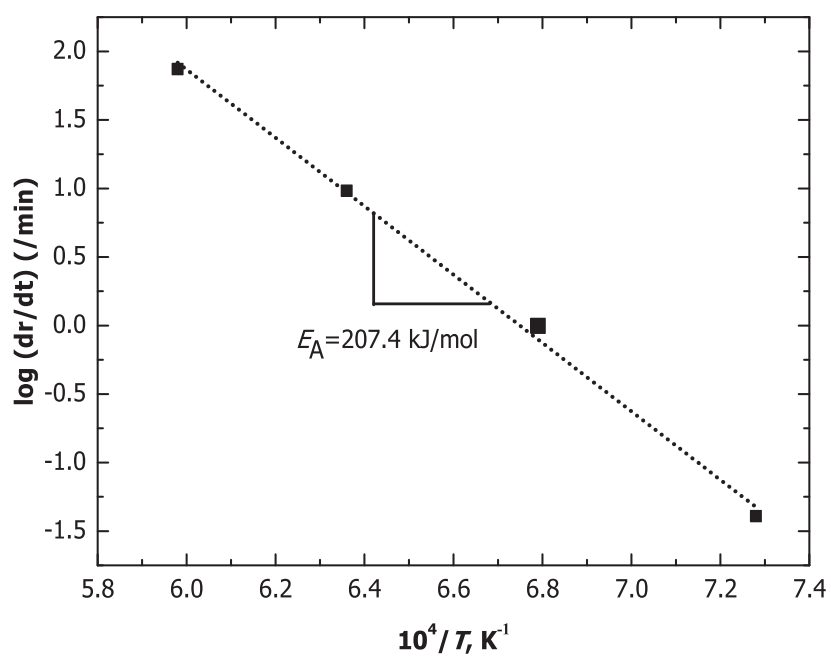

Fig. 7. Arrhenius plot for the second stage in the carbothermic reduction of $\mathrm{MnO}_{2}, \mathrm{Fe}_{2} \mathrm{O}_{3}$ and $\mathrm{Ca}_{3}\left(\mathrm{PO}_{4}\right)_{2}$ at $1200^{\circ} \mathrm{C}$ in $\mathrm{H}_{2}$ atmosphere.

$$
\frac{3}{2}+Z X_{\mathrm{C}}-\frac{3}{2}\left(Z X_{\mathrm{C}}+1\right)^{2 / 3}=\frac{Z k t}{C_{0}(Z+1)\left(r_{\mathrm{MnO}}^{i}\right)^{2}} \ldots .
$$

where $X_{\mathrm{C}}$ is the graphite conversion and the volumetric reaction parameter, $Z$ is defined by Eq. (9): ${ }^{16)}$

$$
Z=\frac{V_{\mathrm{T}}-V_{\mathrm{MnO}}}{V_{\mathrm{MnO}}}
$$

For the mixture used in this experiment, $\mathrm{Z}$ was 2.14. The constant $k$ is a rate constant, $C_{0}$ is the initial concentration of graphite in the mixture and $r_{\mathrm{MnO}}^{i}$ is the radius of $\mathrm{MnO}$ particles. The linear relationship between the conversion of graphite $\left(X_{\mathrm{C}}\right)$ and time was obtained in the range of $0<X_{\mathrm{C}}<$ 0.62 as shown in Fig. 8.

Consequently, the current experimental results are in good agreement with that previously reported. ${ }^{7)}$ In other words, the carburization rate of $\mathrm{MnO}$ and $\mathrm{Fe}$ to $(\mathrm{Mn}, \mathrm{Fe})-$ carbide by graphite in the temperature range of 1100 to $1400^{\circ} \mathrm{C}$ is controlled by the interfacial Boudouard reaction that is the intrinsic diffusion of the intermediate $\mathrm{CO}_{2}$. The amount of phosphorus contained in the sample in the form of $\mathrm{Ca}_{3}\left(\mathrm{PO}_{4}\right)_{2}, 1.33$ mass\%, did not affect the carburization rate of $\mathrm{Mn}$ oxide and $\mathrm{Fe}$ oxide significantly even though the phosphorus amount was higher than most of the manganese ores containing high phosphorous content. The existence of intermediate phosphorus gas produced in the reaction progress might not be involved in the overall carbide formation of $\mathrm{Mn}$ and $\mathrm{Fe}$. In addition, the interaction of phosphorus with metallic Fe and Mn is very strong and fast, ${ }^{17,18)}$ which was not the factor decisively affecting the rate-controlling step.

The chemistry of manganese ores has strong influence on the reduction of the ores. For example, the iron acts as nuclei being able to accelerate the rate of carbide formation and the silica content strongly affects the ore melting temperature, which can significantly affect the reduction rate. ${ }^{11)}$ However, it was clarified in the current investigation that the effect of phosphorus on the carburization of $\mathrm{Mn}$ and $\mathrm{Fe}$ could be negligible compared with the other components in manganese ores in terms of its small amount relatively.

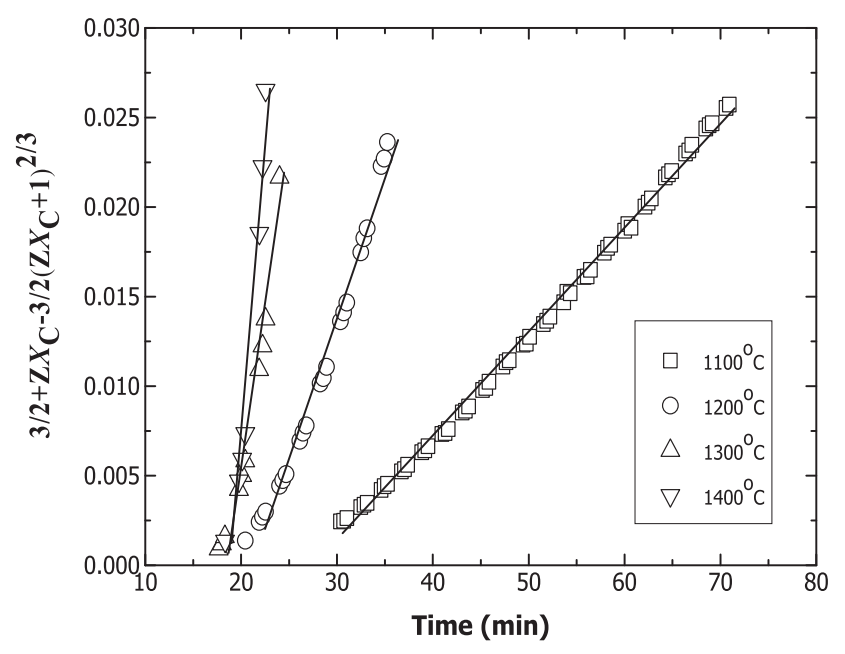

Fig. 8. Application of the Intrinsic transport model.

3.2.2. Progress in the Carbothermic Reduction of $\mathrm{MnO}_{2}$, $\mathrm{Fe}_{2} \mathrm{O}_{3}$ and $\mathrm{Ca}_{3}\left(\mathrm{PO}_{4}\right)_{2}$ at $1200^{\circ} \mathrm{C}$

The isothermal reduction experiments at $1200^{\circ} \mathrm{C}$ in $\mathrm{H}_{2}$ atmosphere were carried out to investigate the reduction mechanism for the points ( $a, b, c$ and d) marked in Fig. 6 . First of all, XRD pattern of each point was analyzed as shown in Fig. 9. The manganese iron carbide started to be formed with the nucleation of $\mathrm{Fe}$ at the reduction time of $15 \mathrm{~min}$, which was followed by the reduction of $\mathrm{MnO}$ to carbide gradually. With $\mathrm{Fe}$ as the nuclei, $(\mathrm{Mn}, \mathrm{Fe})_{5} \mathrm{C}_{2}$ was then formed in the stable lattice of carbide at the time of $40 \mathrm{~min}$. With increasing the reduction time, the peak intensity of $(\mathrm{Mn}, \mathrm{Fe})_{7} \mathrm{C}_{3}$ increased by the diffusion of $\mathrm{Mn}$ into $(\mathrm{Mn}, \mathrm{Fe})_{5} \mathrm{C}_{2}$ at the time of $80 \mathrm{~min}$. It is believed that the carbide preferably formed with $\mathrm{Mn}$ is much more stable due to the higher interactive force between $\mathrm{Mn}$ and carbon compared with that between Fe and carbon. ${ }^{19,20)}$

In addition, the behavior of phosphorus in the progress of reduction with carbon can be estimated by XRD pattern of $\mathrm{Ca}_{3}\left(\mathrm{PO}_{4}\right)_{2}$ and $\mathrm{CaO}$. Some portion of $\mathrm{Ca}_{3}\left(\mathrm{PO}_{4}\right)_{2}$ was about to decompose according to Reaction (10), which was noticed with $\mathrm{CaO}$ peak identified at the time of $40 \mathrm{~min}:^{21}$

$$
\begin{array}{r}
\mathrm{Ca}_{3}\left(\mathrm{PO}_{4}\right)_{2}(s)+5 \mathrm{C}(s)=3 \mathrm{CaO}(s)+\mathrm{P}_{2}(g)+5 \mathrm{CO}(g) \ldots . . \\
\Delta \mathrm{G}^{\mathrm{o}}=1750831-1035.1 T(\mathrm{~J} / \mathrm{mol})^{22)} \ldots \ldots \ldots . .
\end{array}
$$

That is, the reaction temperature of $\mathrm{Ca}_{3}\left(\mathrm{PO}_{4}\right)_{2}$ with carbon at the standard conditions can be calculated to be $1418^{\circ} \mathrm{C}$ from the value of the standard Gibbs free energy of reactions by Eq. (11). However, the reaction can take place at $1200^{\circ} \mathrm{C}$ for the lower partial pressures of product gases in the current experimental conditions. XRD peak of $\mathrm{CaO}$ at 40 min indicates that small amount of $\mathrm{P}_{2}$ gas was generated in the course of carburization although the experimental temperature was lower than $1418^{\circ} \mathrm{C}$. As shown in Table 1, the amount of remained phosphorus in the sample with time shows that a lot of $\mathrm{P}_{2}$ gas was vaporized between Step $\mathrm{b}$ (15 min) and Step c (40 min) which is the starting point of carburization. It could also be supported by the fractional reduction value higher than unity, which was resulted from the additional weight loss due to $\mathrm{P}_{2}$ volatilization from the sample. ${ }^{23,24)}$ In considering the chemical reaction between 
1-C, 2- $\mathrm{MnO}_{2}, 3-\mathrm{Fe}_{2} \mathrm{O}_{3}, 4-\mathrm{Ca}_{3}\left(\mathrm{PO}_{4}\right)_{2}, 5-\mathrm{MnO}, 6-\mathrm{Fe}_{3} \mathrm{O}_{4}, 7-\mathrm{FeO}$

8-Fe, 9-CaO, 10-(Ca,Mn)O, 11-(Mn,Fe $)_{5} \mathrm{C}_{2}, 12-(\mathrm{Mn}, \mathrm{Fe})_{7} \mathrm{C}_{3}$

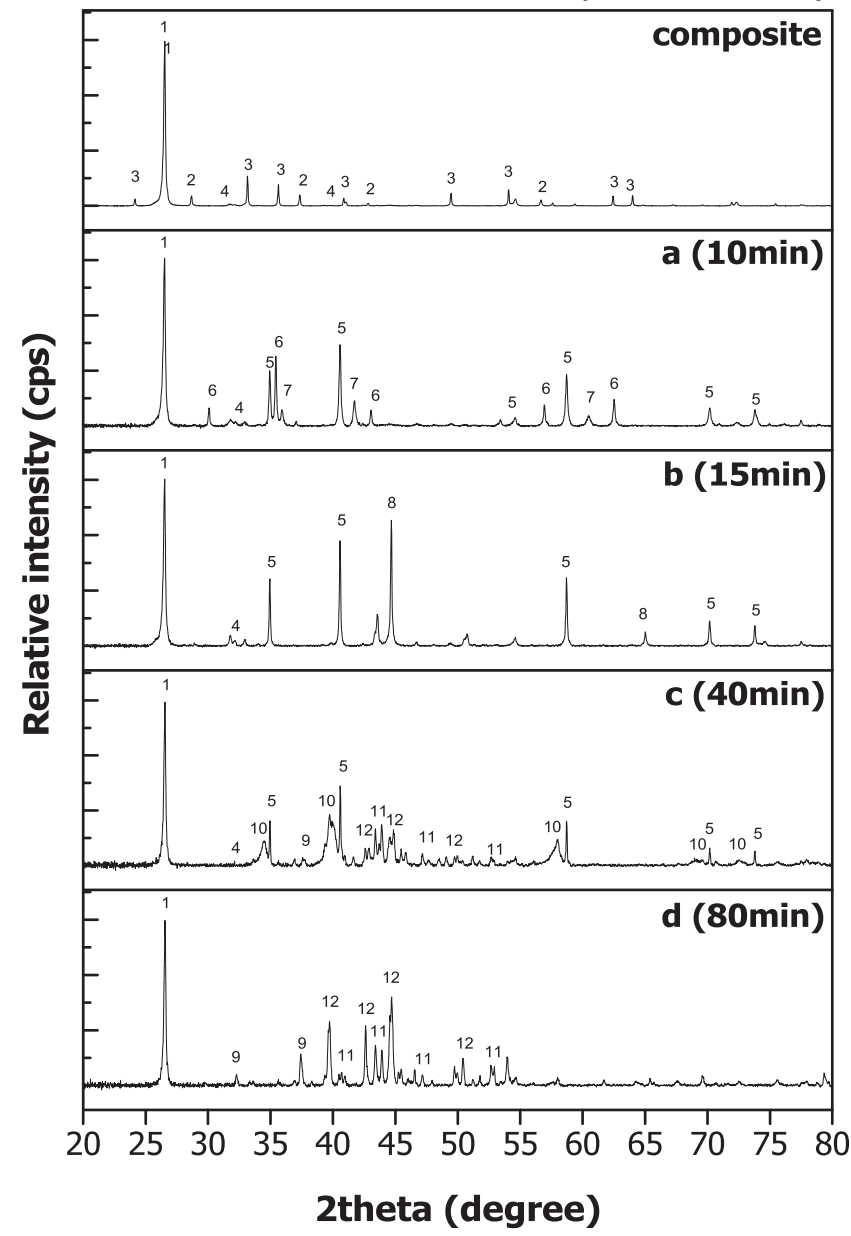

Fig. 9. XRD patterns of the carbothermically reduced sample comprising $\mathrm{MnO}_{2}, \mathrm{Fe}_{2} \mathrm{O}_{3}$ and $\mathrm{Ca}_{3}\left(\mathrm{PO}_{4}\right)_{2}$ samples at $1200^{\circ} \mathrm{C}$ in $\mathrm{H}_{2}$ atmosphere.

Table 1. Phosphorus concentration in carbothermically reduced samples comprising $\mathrm{MnO}_{2}, \mathrm{Fe}_{2} \mathrm{O}_{3}$ and $\mathrm{Ca}_{3}\left(\mathrm{PO}_{4}\right)_{2}$ at $1200^{\circ} \mathrm{C}$ in $\mathrm{H}_{2}$. (a $(10 \mathrm{~min}), \mathrm{b}(15 \mathrm{~min})$, c $(40 \mathrm{~min}), \mathrm{d}$ (80 $\mathrm{min})$ ).

\begin{tabular}{ccccc}
\hline Stages & $\mathrm{a}(10 \mathrm{~min})$ & $\mathrm{b}(15 \mathrm{~min})$ & $\mathrm{c}(40 \mathrm{~min})$ & $\mathrm{d}(80 \mathrm{~min})$ \\
\hline $\mathrm{P}(\mathrm{mass} \%)$ & 1.33 & 1.23 & 0.93 & 0.91 \\
\hline
\end{tabular}

$\mathrm{Ca}_{3}\left(\mathrm{PO}_{4}\right)_{2}$ with $\mathrm{H}_{2}$ as the atmosphere gas, on the other hand, there is no possibility at the experimental temperature according to Eq. (12): ${ }^{25)}$

$$
\begin{aligned}
& 2 \mathrm{CaO} \cdot \mathrm{P}_{2} \mathrm{O}_{5}(\mathrm{~s})+\mathrm{H}_{2}(\mathrm{~g})= \\
& 2 \mathrm{CaO}(\mathrm{s})+\mathrm{P}_{2}(\mathrm{~g})+\mathrm{O}_{2}(\mathrm{~g})+\mathrm{H}_{2} \mathrm{O}(\mathrm{g}) \\
& \Delta G^{\mathrm{o}}=1942600-530.2 T(\mathrm{~J} / \mathrm{mol})^{22)}
\end{aligned}
$$

The morphology of $\mathrm{MnO}_{2}, \mathrm{Fe}_{2} \mathrm{O}_{3}$ and $\mathrm{Ca}_{3}\left(\mathrm{PO}_{4}\right)_{2}$ in the sample reduced and carburized at $1200^{\circ} \mathrm{C}$ in $\mathrm{H}_{2}$ was observed by FE-SEM. As shown in Fig. 10, the change of morphology in the first stage was investigated for the points $a$ and $b$ shown in Fig. 6 and the elemental compositions of selected points were analyzed by EDS as summarized in Table 2. The elemental analyses of the points on FE-SEM images by EDS were assumed to correspond to some com-
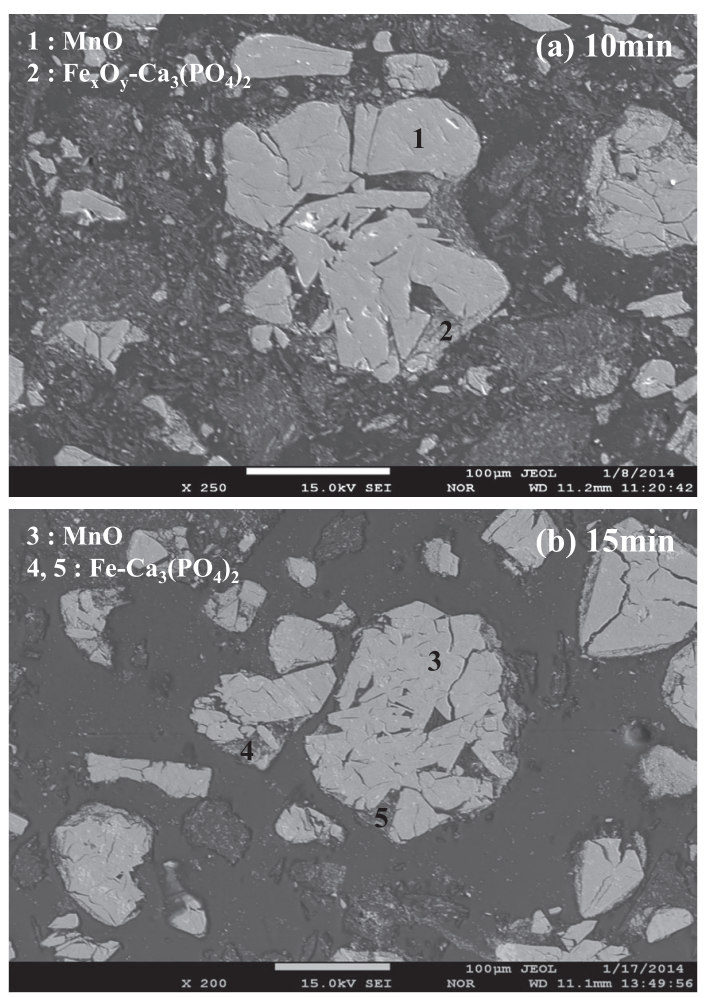

Fig. 10. SEM images of the carbothermically reduced sample comprising $\mathrm{MnO}_{2}, \mathrm{Fe}_{2} \mathrm{O}_{3}$ and $\mathrm{Ca}_{3}\left(\mathrm{PO}_{4}\right)_{2}$ samples at $1200^{\circ} \mathrm{C}$ in $\mathrm{H}_{2}$ atmosphere in the first stage (a (10 min), b (15 $\mathrm{min})$ ).

Table 2. Elemental analyses of the carbothermically reduced sample comprising $\mathrm{MnO}_{2}, \mathrm{Fe}_{2} \mathrm{O}_{3}$ and $\mathrm{Ca}_{3}\left(\mathrm{PO}_{4}\right)_{2}$ in the first stage (a (10 $\mathrm{min}), \mathrm{b}(15 \mathrm{~min}))$ by EDS.

\begin{tabular}{ccccccc}
\hline \multirow{2}{*}{ Time (min) } & Position & \multicolumn{5}{c}{$\mathrm{at} \%$} \\
\cline { 2 - 7 } & & $\mathrm{Mn}$ & $\mathrm{Fe}$ & $\mathrm{P}$ & $\mathrm{Ca}$ & $\mathrm{O}$ \\
\hline \multirow{2}{*}{$\mathrm{a}(10 \mathrm{~min})$} & 1 & 54.83 & - & - & - & 45.17 \\
& 2 & - & 36.97 & 3.40 & 6.32 & 53.31 \\
\hline $\mathrm{b}(15 \mathrm{~min})$ & 3 & 54.67 & - & - & - & 45.33 \\
& 4 & - & 16.42 & 10.81 & 18.13 & 54.65 \\
& 5 & - & 28.36 & 7.40 & 13.93 & 50.31 \\
\hline
\end{tabular}

(Note) The carbon content in the selected area is not included.

pounds with the help of XRD patterns. In the beginning of reduction, the reduced $\mathrm{MnO}$ with dense and large blocks exists as a main dominant phase and the particle mixture of $\mathrm{Fe}$ oxide, $\mathrm{Ca}_{3}\left(\mathrm{PO}_{4}\right)_{2}$ and carbon surrounds the reduced $\mathrm{MnO}$. Further reaction reduced Fe oxide to metallic Fe by $\mathrm{H}_{2}$ from Step (a) to Step (b) where the reduction in the first stage was finished.

The FE-SEM images of particles in the second stage at the reduction time of 40 and 80 min were shown in Fig. 11 and elemental analysis results of the selected points were presented in Table 3. In this stage, the carbide was about to form with the nucleation of Fe surrounding the reduced $\mathrm{MnO}$. In Fig. 11, it was observed that $\mathrm{MnO}$ particles broke into smaller oxide blocks and generated numerous cracks, which indicates that $\mathrm{MnO}$ might be reduced. The carbide and $\mathrm{MnO}$ phases were simultaneously identified in XRD pattern for Step (c), which implys that the reduction of $\mathrm{MnO}$ and carbide formation could have simultaneously proceed. 

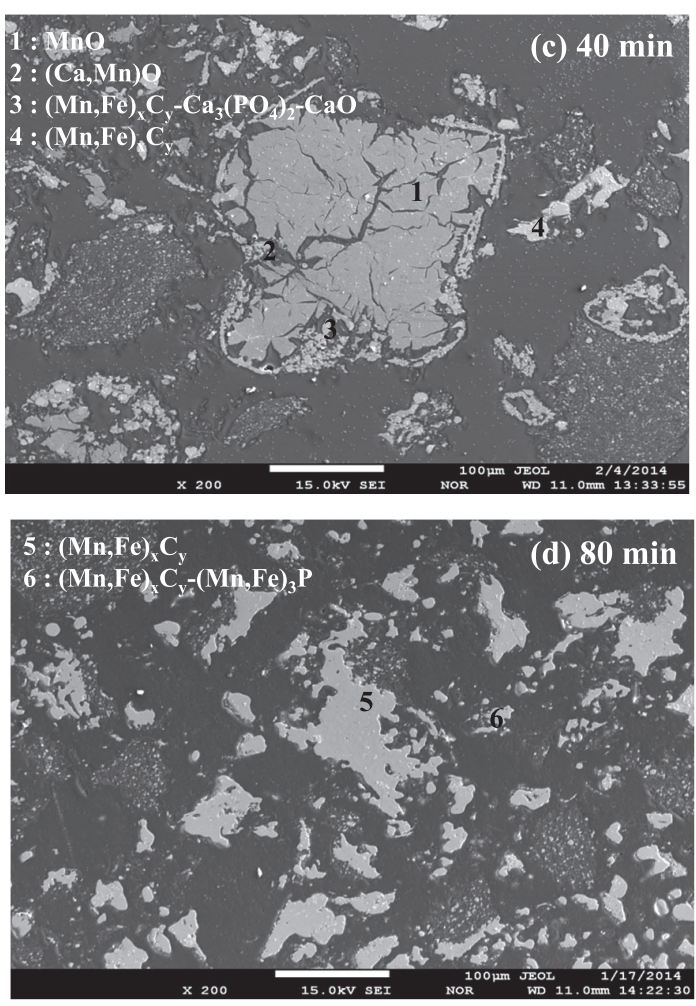

Fig. 11. SEM images of the carbothermically reduced sample comprising $\mathrm{MnO}_{2}, \mathrm{Fe}_{2} \mathrm{O}_{3}$ and $\mathrm{Ca}_{3}\left(\mathrm{PO}_{4}\right)_{2}$ samples at $1200^{\circ} \mathrm{C}$ in $\mathrm{H}_{2}$ atmosphere in the second stage (c $(40 \mathrm{~min})$, $\mathrm{d}(80 \mathrm{~min}))$.

Table 3. Elemental analyses of the carbothermically reduced sample comprising $\mathrm{MnO}_{2}, \mathrm{Fe}_{2} \mathrm{O}_{3}$ and $\mathrm{Ca}_{3}\left(\mathrm{PO}_{4}\right)_{2}$ in the second stage (c (40 $\mathrm{min}), \mathrm{d}(80 \mathrm{~min}))$ by EDS.

\begin{tabular}{ccccccc}
\hline \multirow{2}{*}{ Time (min) } & Position & \multicolumn{5}{c}{ at\% } \\
\cline { 2 - 7 } & & Mn & Fe & P & Ca & O \\
\hline & 1 & 57.55 & - & - & - & 42.46 \\
c (40 min) & 2 & 47.03 & - & - & 7.53 & 43.56 \\
& 3 & 47.53 & 9.08 & 3.21 & 7.28 & 32.90 \\
& 4 & 81.25 & 18.75 & - & - & - \\
\hline & 5 & 86.85 & 13.15 & - & - & - \\
\hline
\end{tabular}

(Note) The carbon content in the selected area is not included.

At the completion of reduction for Step (d), it appeared that all the $\mathrm{MnO}$ was reduced and that the formed manganese iron carbides were sintered. It is believed that most of the particles comprise the mixture of $(\mathrm{Mn}, \mathrm{Fe})$-carbide and (Fe,Mn)-phosphide surrounded by $\mathrm{CaO}$ and $\mathrm{Ca}_{3}\left(\mathrm{PO}_{4}\right)_{2}$ according to the EDS results and XRD patterns. In addition, $(\mathrm{Fe}, \mathrm{Mn})_{3} \mathrm{P}$ could be resulted from the reaction between metallic $(\mathrm{Fe}, \mathrm{Mn})$ and $\mathrm{P}_{2}$ gas generated from $\mathrm{Ca}_{3}\left(\mathrm{PO}_{4}\right)_{2}{ }^{26)}$

\subsubsection{Estimation of Carbothermic Reduction Mechanism of $\mathrm{MnO}_{2}, \mathrm{Fe}_{2} \mathrm{O}_{3}$ and $\mathrm{Ca}_{3}\left(\mathrm{PO}_{4}\right)_{2}$ at $1200^{\circ} \mathrm{C}$ by EPMA Mapping Analysis}

For clearer evidence, the area and line mappings by EPMA were conducted. Figure 12 indicates the elemental distribution in the samples obtained at the reduction time of 15 and $40 \mathrm{~min}$, respectively, in the stage of carbide forma- tion. In the beginning for $15 \mathrm{~min}, \mathrm{MnO}_{2}$ was completely reduced to $\mathrm{MnO}$ and then diffused into the particles which include Fe surrounding $\mathrm{MnO}$, resulting in the formation of carbide. This progress can be confirmed by the increase of $\mathrm{Mn}$ content in $\mathrm{Fe}-\mathrm{C}$ mixture while further reduction was performed with the growth of carbide. Due to the decomposition of $\mathrm{Ca}_{3}\left(\mathrm{PO}_{4}\right)_{2}$ during carburization, the concentration of phosphorus at $40 \mathrm{~min}$ slightly decreased compared with that at $15 \mathrm{~min}$. However, it is believed that the diffusion of $\mathrm{Ca}$ did not occur since the concentration of $\mathrm{Ca}$ remained unchanged despite the decomposition of $\mathrm{Ca}_{3}\left(\mathrm{PO}_{4}\right)_{2}$.

The mixture of $\mathrm{Fe}$ and carbon around particles cannot form the carbide without $\mathrm{Mn}$ due to the carbon deposition and unstable state of iron carbide at high temperatures. ${ }^{27)}$ However, it can be stabilized by the substitution of Mn into the lattice. ${ }^{28)}$ It indicates that the carbide should be formed along with the diffusion of $\mathrm{Mn}$, which can proceed by overcoming the space existing between $\mathrm{MnO}$ and $\mathrm{Fe}-\mathrm{C}$ mixture. It is believed that $\mathrm{Fe}-\mathrm{C}$ mixture could easily contact the surface of $\mathrm{MnO}$ since it was in liquid state at $1200^{\circ} \mathrm{C}$ as shown in Fig. 13. This mechanism can be supported by the overall formation of $\mathrm{Mn}$ carbide in terms of the following reactions: ${ }^{29)}$

$$
\begin{array}{r}
7 \mathrm{MnO}(\mathrm{s})+10 \mathrm{C}(\mathrm{s})=\mathrm{Mn}_{7} \mathrm{C}_{3}(\mathrm{~s})+7 \mathrm{CO}(\mathrm{g}) \\
7 \mathrm{MnO}(\mathrm{s})+13 \mathrm{CO}(\mathrm{g})=\mathrm{Mn}_{7} \mathrm{C}_{3}(\mathrm{~s})+10 \mathrm{CO}_{2}(\mathrm{~g}) \ldots \\
10 \mathrm{CO}_{2}(\mathrm{~g})+10 \mathrm{C}(\mathrm{s})=20 \mathrm{CO}(\mathrm{g}) \ldots \ldots \ldots
\end{array}
$$

In other words, $\mathrm{CO}$ supplied by the Boudouard reaction reduced $\mathrm{MnO}$ to produce $\mathrm{Mn}$ which diffused to the melt of $\mathrm{Fe}-\mathrm{C}$ mixture. Then $\mathrm{Mn}$ could react with $\mathrm{Fe}$ and carbon to form manganese iron carbide. The formation of the final stable phase of manganese iron carbide at the equilibrium state was carried out by the following reaction:

$$
7 \mathrm{MnO}(s)+(\mathrm{Fe}-\mathrm{C}) \operatorname{melt}(l)=(\mathrm{Mn}, \mathrm{Fe})_{7} \mathrm{C}_{3}(s)+7 \mathrm{CO}(g)
$$

It can be considered that the $\mathrm{Fe}-\mathrm{C}$ melt can react with $\mathrm{P}_{2}$ gas more easily than the solid state, and the formation of (Fe, Mn)-phosphide might be accompanied by $(\mathrm{Mn}, \mathrm{Fe})$ carbide formation simultaneously. However, this possibility was considered based on the previously reported results. ${ }^{11,15)}$ More in-depth understanding of the direct formation mechanism requires further investigation.

Around the completion of reduction at the reduction time of $80 \mathrm{~min}$, the elemental distribution through the EPMA mapping was obtained for the products of carburized $\mathrm{MnO}_{2}$, $\mathrm{Fe}_{2} \mathrm{O}_{3}$ and $\mathrm{Ca}_{3}\left(\mathrm{PO}_{4}\right)_{2}$ as shown in Fig. 14. Mn and Fe were found at the similar location, which indicates that most of the particles consisted of $(\mathrm{Mn}, \mathrm{Fe})$-carbide in the presence of carbon and ( $\mathrm{Mn}, \mathrm{Fe})$-phosphide in the presence of phosphorus. In the FE-SEM images, the sintering of ( Mn,Fe)-carbide and $(\mathrm{Mn}, \mathrm{Fe})$-phosphide indiscriminately in one particle can be assumed. The diffusion of Mn to carbide phase and the reaction of vaporized $\mathrm{P}_{2}$ gas with $\mathrm{Fe}-\mathrm{C}$ melt was carried out simultaneously. The area of carbon existing with $\mathrm{Mn}$ and $\mathrm{Fe}$ was believed to represent carbide even though the distribution of carbon in the particle was not distinctive due to the relative high amount of carbon in resin. On the other hand, 

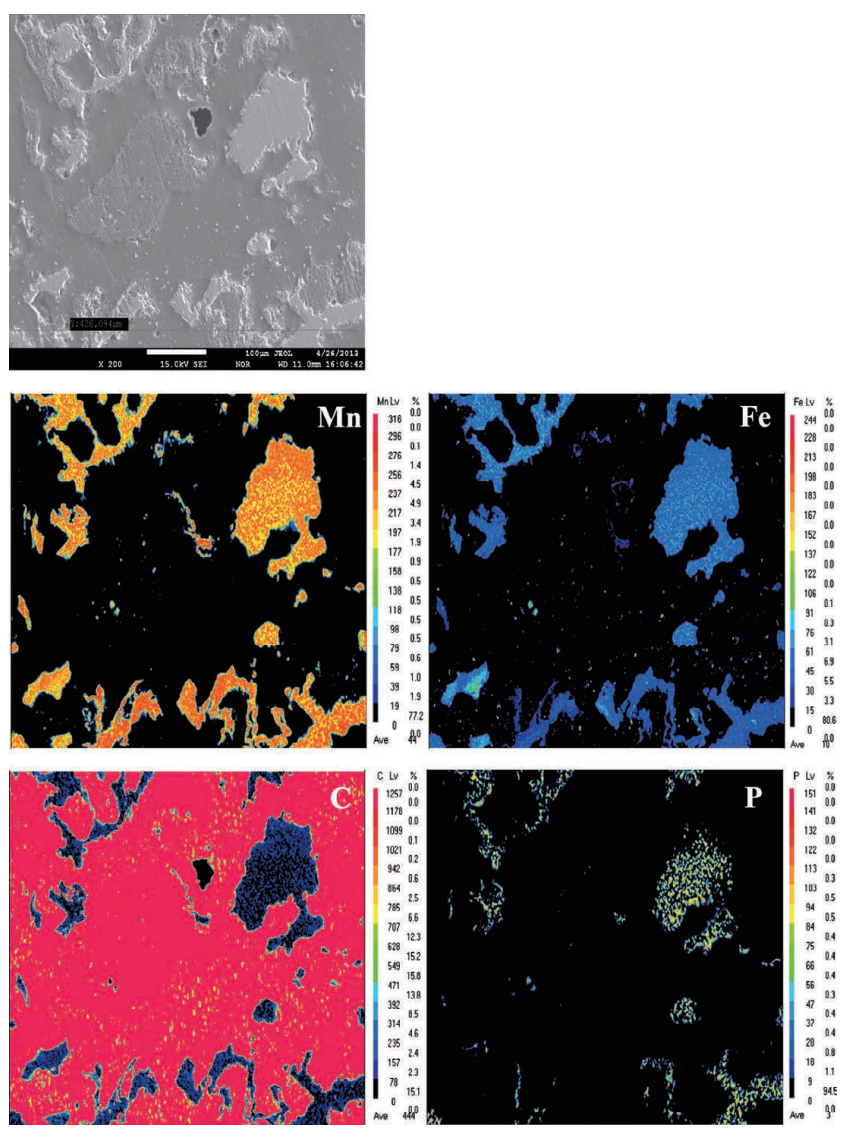

Fig. 4. EPMA area mapping of the carbothermically reduced sample comprising $\mathrm{MnO}$ and $\mathrm{Fe}_{3} \mathrm{P}$ at $1200^{\circ} \mathrm{C}$ in $\mathrm{H}_{2}$ atmosphere.
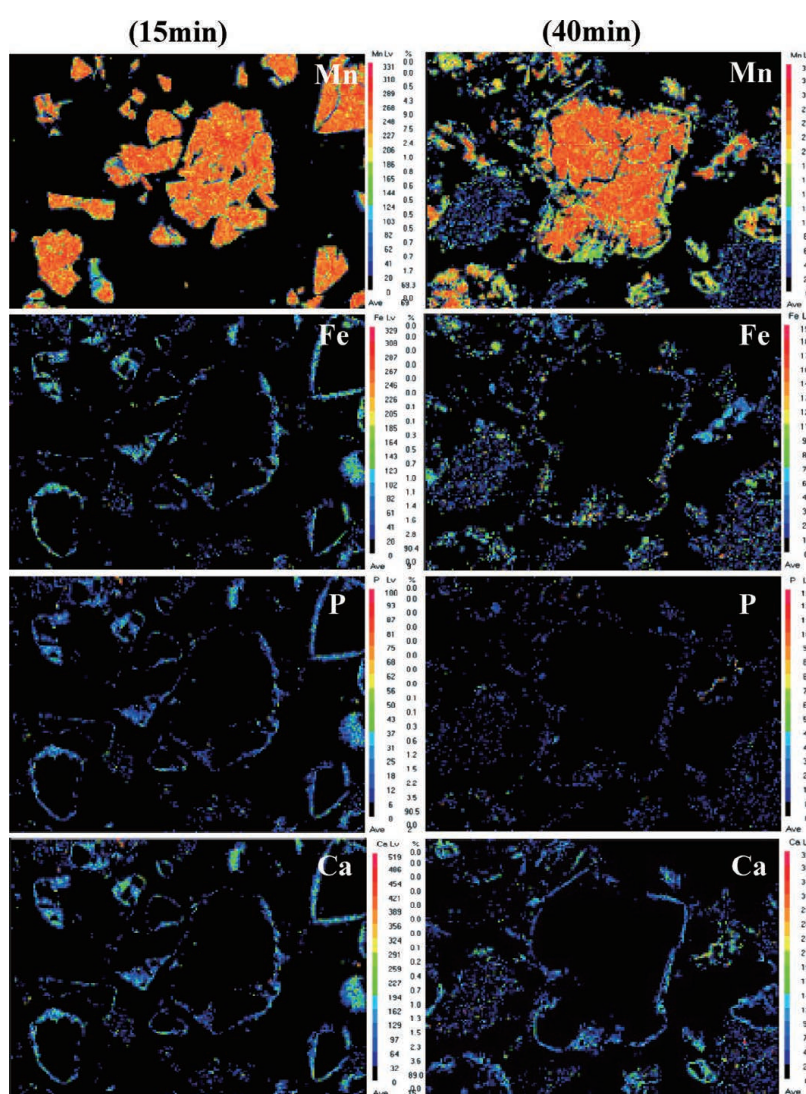

Fig. 12. EPMA area mapping of the carbothermically reduced sample comprising $\mathrm{MnO}_{2}, \mathrm{Fe}_{2} \mathrm{O}_{3}$ and $\mathrm{Ca}_{3}\left(\mathrm{PO}_{4}\right)_{2}$ samples at $1200^{\circ} \mathrm{C}$ in $\mathrm{H}_{2}$ atmosphere (b $(15 \mathrm{~min})$, c (40 min)).

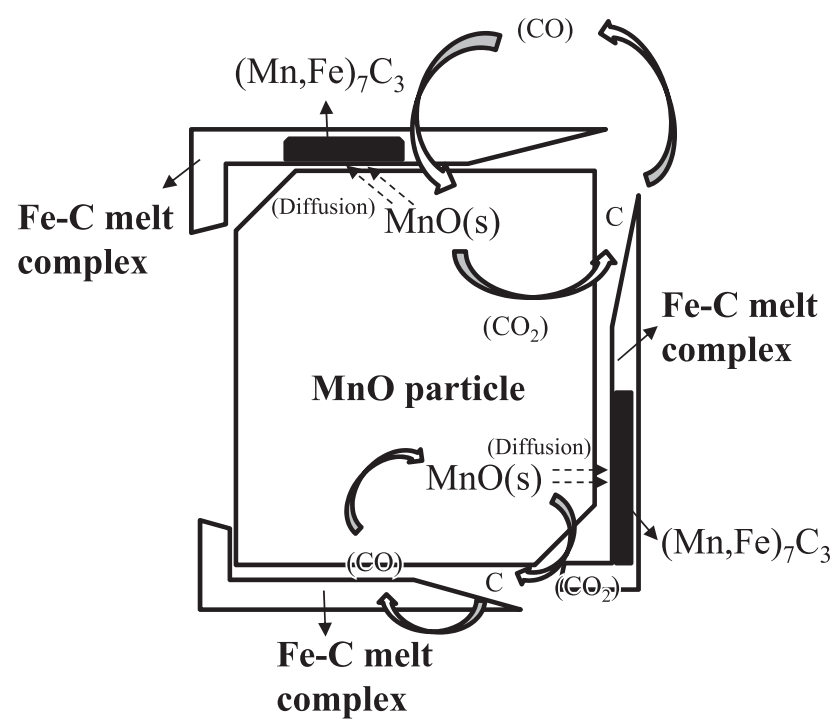

Fig. 13. Reaction mechanism for the carburization of $\mathrm{MnO}$ on the $\mathrm{Fe}-\mathrm{C}$ surface.
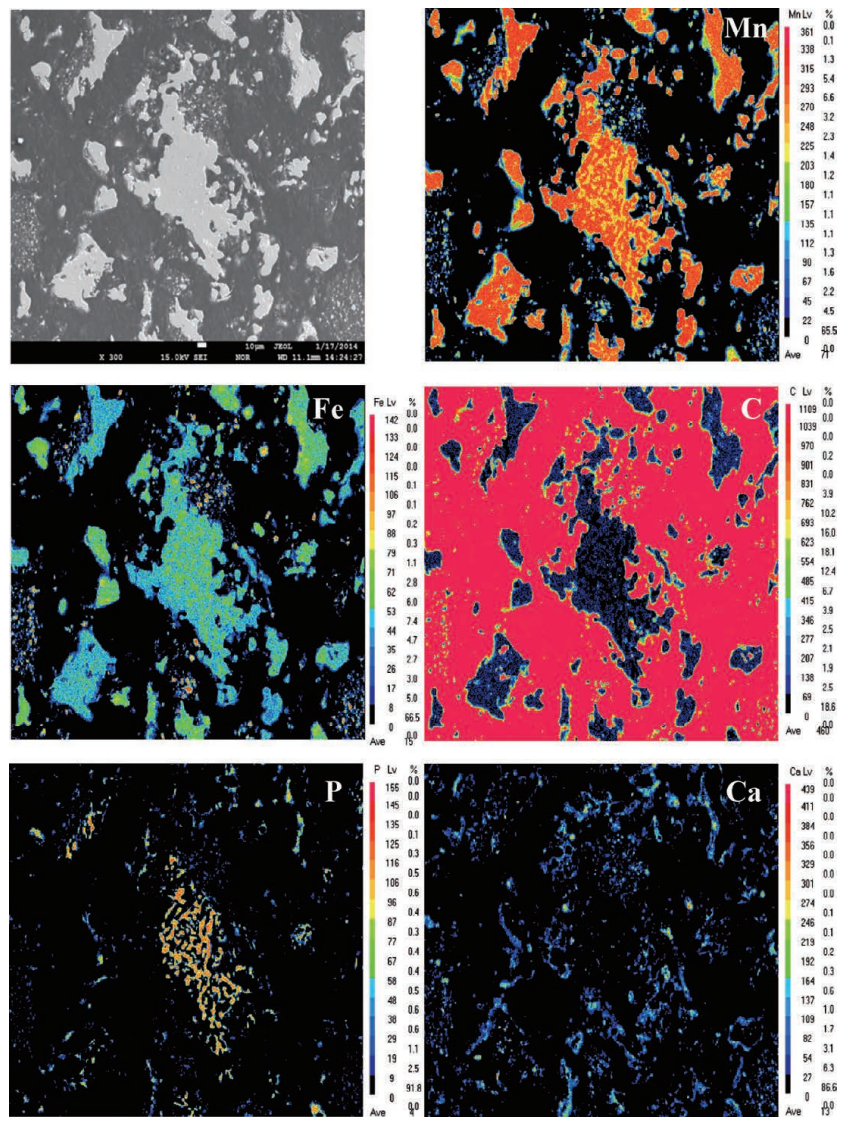

Fig. 14. EPMA area mapping of the carbothermically reduced sample comprising $\mathrm{MnO}_{2}, \mathrm{Fe}_{2} \mathrm{O}_{3}$ and $\mathrm{Ca}_{3}\left(\mathrm{PO}_{4}\right)_{2}$ samples at $1200^{\circ} \mathrm{C}$ in $\mathrm{H}_{2}$ atmosphere $(\mathrm{d}(80 \mathrm{~min}))$.

the phosphorus exists in the form of two compounds, either $\mathrm{Ca}_{3}\left(\mathrm{PO}_{4}\right)_{2}$ with $\mathrm{Ca}$ or $(\mathrm{Fe}, \mathrm{Mn})_{3} \mathrm{P}$ with $\mathrm{Fe}$ and $\mathrm{Mn}$. It is believed that $\mathrm{Ca}_{3}\left(\mathrm{PO}_{4}\right)_{2}$ usually distributes around particles, which was identified from the overlapped area of $\mathrm{P}$ and $\mathrm{Ca}$ distribution. On the other hand, $\mathrm{Ca}$ identified in the mapping seemed to originate from the $\mathrm{CaO}$ decomposed from $\mathrm{Ca}_{3}\left(\mathrm{PO}_{4}\right)_{2}$.

There is no clear distinction between the distribution of 

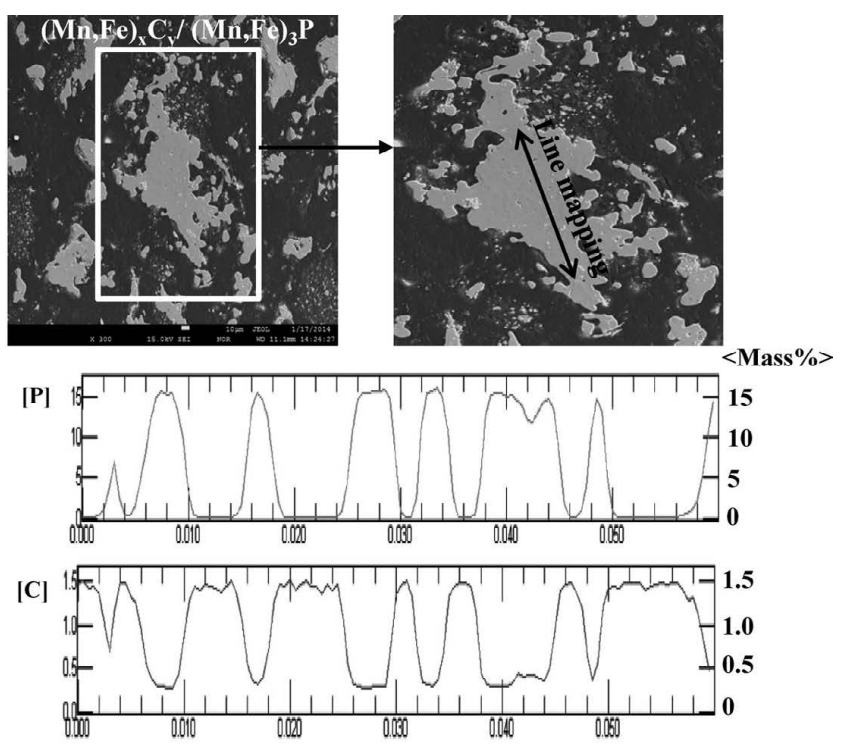

$[\mathrm{Fe}]$
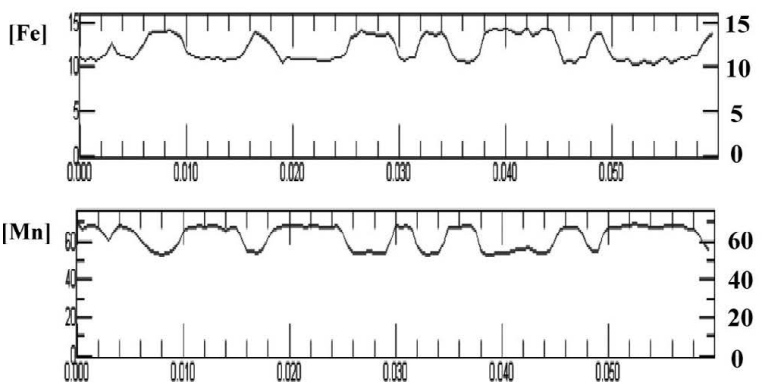

Fig. 15. EPMA line mappings (mass\%) of the carbothermically reduced sample comprising $\mathrm{MnO}_{2}, \mathrm{Fe}_{2} \mathrm{O}_{3}$ and $\mathrm{Ca}_{3}\left(\mathrm{PO}_{4}\right)_{2}$ samples at $1200^{\circ} \mathrm{C}$ in $\mathrm{H}_{2}$ atmosphere $(\mathrm{d}(80 \mathrm{~min}))$.

( $\mathrm{Mn}, \mathrm{Fe})$-carbide and that of (Fe,Mn)-phosphide in the EPMA area mapping. Hence, the EPMA line mapping was carried out for the clearer distribution of the elements in the particle containing carbide and $(\mathrm{Fe}, \mathrm{Mn})_{3} \mathrm{P}$ as shown in Fig. 15. From the opposite distribution of carbon and phosphorus in the line profile, it is believed that the carbide does not overlap the phosphide although two compounds coexist within one particle. That is, phosphorus does not dissolve into carbide, which strongly indicates that phosphorus is not involved in the formation of carbide. The magnetic properties of manganese iron carbide is changed by the ratio of $\mathrm{Mn}$ to Fe, and the ferromagnetic (Mn,Fe)-carbide can be separated from the antiferromagnetic $(\mathrm{Mn}, \mathrm{Fe})$-phosphide with the help of the magnetic separator with mechanical crushing. In conclusion, the formation of carbide with high carbon content might be helpful not only for the removal of phosphorus, but also for the incorporation of $\mathrm{Mn}$ and $\mathrm{Fe}$ into the lattice of carbide.

\section{Conclusions}

The carbothermic reduction of Mn oxide, Fe oxide and phosphorus compounds was investigated to utilize the manganese iron carbide for the dephosphorization of high $\mathrm{P}$ manganese ores. From the findings, the following conclusions were obtained:

(1) In the carburization of $\mathrm{MnO}$ and $\mathrm{Fe}_{3} \mathrm{P}$ at $1200^{\circ} \mathrm{C}$,
Mn and Fe substituted each other during the formation of carbide. However, the carbon and phosphorus did not dissolve each other and reacted with $\mathrm{Mn}$ and $\mathrm{Fe}$ to $(\mathrm{Mn}, \mathrm{Fe})_{7} \mathrm{C}_{3}$ or $(\mathrm{Fe}, \mathrm{Mn})_{3} \mathrm{P}$, respectively.

(2) The carbothermic reduction of $\mathrm{MnO}_{2}, \mathrm{Fe}_{2} \mathrm{O}_{3}$ and $\mathrm{Ca}_{3}\left(\mathrm{PO}_{4}\right)_{2}$ was carried out in the temperature range 1100 to $1400^{\circ} \mathrm{C}$ in $\mathrm{H}_{2}$ atmosphere to for the determination of rate controlling step. The carburization rate was limited by the intrinsic diffusion of the intermediate $\mathrm{CO}_{2}$ in the Boudouard reaction as is similar to the previously reported results. Namely, the reaction of phosphorus with metallic $(\mathrm{Mn}, \mathrm{Fe})$ did not affect the overall formation rate of manganese iron carbide.

(3) $\mathrm{P}_{2}$ gas generated from the decomposition of $\mathrm{Ca}_{3}\left(\mathrm{PO}_{4}\right)_{2}$ reacted with diffused $\mathrm{Mn}$ to form $(\mathrm{Fe}, \mathrm{Mn})_{3} \mathrm{P}$ using $\mathrm{Fe}$ in $\mathrm{Fe}-\mathrm{C}$ melt as a nucleation site. From the opposite distribution of carbon and phosphorus in the EPMA line profile, the carbide does not overlap the phosphide although two compounds coexist within one particle. This might suggest that phosphorus is not involved in the formation of carbide.

\section{REFERENCES}

1) S. E. Olsen, M. Tangstad and T. Lindstad: Production of Manganese Ferroalloys, SINTEF and Tapir Academic Press, Trondheim, Norway, (2007), 46.

2) S. C. Shim and N. Sano: Thermodynamics of Phosphorus in CarbonSaturated Manganese-based Alloys, FFF, Trondheim, Norway, (1995), 611.

3) R. Kononov, O. Ostrovski and S. Ganguly: ISIJ Int., 49 (2009), 1107.

4) J. Lehmann, H. Gaye and F. Bonnet: Thermodynamics Applied to Ferro-Alloys Smelting, Document Transformation Technologies, Cape Town, South Africa, (2004), 307.

5) B. C. DeCooman, J. G. Speer, I. Pyshmintsev and N. Yoshinaga: Mater. Design, 2 (2007), 150.

6) F. Claeyssens, G. M. Fuge, N. L. Allan, P. W. May and M. N. R. Ashfold: Dalton Trans., 7 (2004), 3085.

7) M. Yastreboff, O. Ostrovski and S. Ganguly: ISIJ Int., 43 (2003), 161.

8) D. Djurovi, B. Hallstedt, J. v. Appen and R. Dronskowski: Calphad, 35 (2011), 479.

9) N. Anacleto, O. Ostrovski and S. Ganguly: ISIJ Int., 44 (2004), 1480.

10) S. Bai, S. Wen, D. Liu, W. Zhang and Q. Cao: ISIJ Int., 52 (2012), 1757.

11) R. Kononov, O. Ostrovski and S. Ganguly: ISIJ Int., 49 (2009), 1115.

12) A. K. Biswas: Principles of Blast Furnace Ironmaking, SBA Pub., Calcutta, India, (1981), 70.

13) G. J. W. Kor: Metall. Trans. B, 9B (1978), 307.

14) W. J. Rankin and J. S. J. Van Deventer: J. S. Afr. Inst. Min. Metall., 80 (1980), 239.

15) J. R. Wynnyckyj and W. J. Rsukin: Metall. Trans. B, 19B (1988), 73.

16) W. J. Rankin and J. R. Wynnyckyj: Metall. Trans. B, 28B (1997), 307.

17) A. K. Shurin and N. A. Razumova: Powder Metall. Metal C., 32 (1993), 921.

18) A. I. Zaitsev and B. M. Mogutnov: ISIJ Int., 32 (1992), 1076.

19) A. Brahmi and R. Borrelly: Scr. Mater., 32 (1995), 365.

20) Y. Zhang and D. M. Schleich: J. Solid State Chem., 110 (1994), 270.

21) X. H. Huang: Iron and Steel Metallurgy Principles, Metallurgy Industry Press, Beijing, (1981), 437.

22) R. J. Fruehan: The Making, Shaping and Treating of Steel, Steelmaking and Refining Volume, 11th ed., AISE Steel Foundation, Pittsburgh, PA, (1998), 20.

23) E. Matinde and M. Hino: ISIJ Int., 51 (2011), 220.

24) J. Yin, X. Lv, C. Bai, G. Qiu, S. Ma and B. Xie: ISIJ Int., 52 (2012), 1579.

25) H. Lee: Chemical Thermodynamics for Metal and Materials, Imperial College Press, London, (1999), 284.

26) Y. E. Lee: Metall. Trans. B, 17B (1986), 777.

27) J. Zhang and O. Ostrovski: Cementite Formation and Its Stability in Iron Carbide Process, 59th Ironmaking Confe. Proc., ISS, Warrendale, PA, (2000), 339.

28) J. Briki and S. B. Slima: J. Metallurgy, 2012 (2012), 1.

29) R. Kononov, O. Ostrovski and S. Ganguly: ISIJ Int., 49 (2009), 1099. 